\title{
Which Patient with Reflux Should Undergo Surgery?
}

\section{Hangi Reflü Hastası Ameliyat Olmalı?}

\author{
(iD Adem AKÇAKAYA
}

Bezmialem Vakıf University Faculty of Medicine, Department of General Surgery, İstanbul, Turkey

\section{Dear Readers,}

In this article, I will talk about reflux disease, its symptoms, diagnosis, treatment methods and which patients should be treated with surgery.

Gastroesophageal reflux disease (GERD) is a common disease in developed and developing societies $(1,2)$. Reflux disease is the reflux of acidic stomach contents into the esophagus. Sometimes, stomach contents may contain pepsin, pancreatic enzymes, bile and foods in addition to acid. This backflow irritates the lining of the esophagus. Most people may experience physiological acid reflux from time to time (2). It is reported that the incidence of reflux in the world is around $20 \%$. In our country, it has been determined that it is slightly more than $25 \%$, although it varies according to the regions. This means that one out of four people has reflux.

Gastroesophageal reflux disease is an important disease that causes significant physical and psychological problems with the disturbing symptoms it causes, and surgical treatment is frequently used in addition to medical treatment in its treatment $(3,4)$. Although symptom control is achieved in a large patient group with the appropriate use of medical treatment, symptom control is not possible at a rate of $30-40 \%$ with a significant decrease in quality of life despite medical treatment (5). Although medical treatment is effective in controlling heartburn, it may be insufficient to control regurgitation and respiratory symptoms, especially in patients with GERD accompanied by hiatal hernia. In addition, chronic complications of GERD such as stricture and Barrett's esophagus despite medical treatment, as well as the risk of developing adenocarcinoma on the basis of Barrett's esophagus contribute to the uncertainty in the treatment of the disease.
Although the effectiveness of medical treatment for GERD is known, the side effects of drugs, the cost of long-term drug use and its negative effects on the patient, the decrease in the quality of life of the patients, and the surgical treatment option come to the fore especially in patients in whom drugs fail in symptom control or symptoms recur (3).

Heartburn and regurgitation are the two most important symptoms of GERD, either alone or together. Although these two typical symptoms are seen in almost all patients, it should be kept in mind that irritable bowel syndrome, functional dyspepsia, esophageal hypersensitivity and other somatoform disorders may cause reflux-like complaints. It is known that atypical symptoms such as nausea, belching, slow digestion, early satiety, epigastric pain, bloating, vomiting, precordial catch syndrome, cough, wheezing, chronic rhinosinusitis, hoarseness and hoarse voice are among the complaints of these patients.

The diagnosis can be made based on the anamnesis and findings. However, it is of great importance to make the differential diagnosis of other diseases in this region before the operation. To diagnose and determine the severity of the disease; gastroscopy, $\mathrm{pH}$ measurement, contrast radiographs, and manometric studies are performed. The two most important diagnostic tests to confirm the diagnosis of GERD are endoscopy and $\mathrm{pH}$ and esophageal impedance monitoring. Manometer is used in the evaluation of disorders such as achalasia and ineffective esophageal motility before surgical treatment rather than diagnosis. In patients with large hiatal hernia, barium examinations are helpful in revealing the anatomy and detecting the short esophagus. It is stated that choosing the appropriate patient and the most appropriate technique with the help of the obtained data, as well as ensuring 
that the surgery to be performed by an experienced surgeon are important for the success of the treatment (3).

Reflux can usually be controlled with lifestyle changes, nutritional support, phytotherapy and supplements. But some people need stronger medications or surgery to relieve symptoms. The aim of treatment in reflux disease is to control the complaints, heal the damage in the esophagus and prevent complications. The course of the disease is variable in each patient and requires a different approach. It is of great importance to decide which patient will be treated with medication, diet and other methods and which patient will be operated on.

In the first stage of reflux treatment; diet regulation, drugs that suppress stomach acid and changes in lifestyle are tried. Raising the head of the bed by $15 \mathrm{~cm}$, sleeping on the left side at night, reducing food consumption that may cause reflux, not eating until at least 3 hours before bedtime, losing excess weight, not wearing tight clothes, reducing smoking, coffee and alcohol consumption are the changes that can be made in lifestyle.

In recent years, some endoscopic treatment methods have been used to strengthen the lower esophageal sphincter in the treatment of reflux. Endoscopic gastroplasty (EndoCinch) and radiofrequency energy application (Stretta method) can be counted among these. Although some centers apply these methods quite successfully, they are not yet included in routine practice.

Before deciding on surgical treatment in a patient with reflux, it is necessary to clearly determine whether the patient needs longterm reflux treatment. Surgical treatment is a method used in approximately $10 \%$ of patients with reflux.

Laparoscopic antireflux surgery is recommended for patients with a persistent decrease in quality of life and persistent bothersome symptoms, especially if the disease progresses or symptoms cannot be controlled despite proton pump inhibitor therapy. It is stated that surgical treatment may be preferred more if the following criteria are met: $(1,3)$

- Typical symptoms of GERD

- Demonstrating the relationship between symptom and reflux

- History longer than one year

- Decreased quality of life

- Response to proton pump inhibitor therapy

- Increasing the proton pump inhibitor treatment dose

- Hiatal hernia

- Presence of esophagitis endoscopically before treatment

- Demonstration of lower esophageal sphincter insufficiency

- Demonstrating acid reflux

In anti-reflux surgery, the valve system where the esophagus meets the stomach is strengthened. The functional antireflux barrier to be created during surgical treatment has 3 important components: Adequate length of the intra-abdominal esophagus, repair of the crura, and fundoplication. In this method, which is called fundoplication in the medical literature, the stomach is wrapped around the esophagus. This wrap can be applied at 180 (Dorr), 270 (Toupet) or 360 (Nissen) degrees.

Although a limited number of randomized controlled studies have shown that partial fundoplication causes less short-term side effects, long-term results are still lacking (6). Therefore, an experienced surgeon working in a high-volume center should decide on his/her own experience and conclusions whether the procedure to be performed will be total or partial fundoplication.

In the Japanese guideline, laparoscopic Toupet fundoplication is recommended as the standard surgical technique for GERD (7). Most frequently, publications compare laparoscopic Nissen fundoplication with posterior partial Toupet hemifundoplication. Their superiority over each other is defined differently in different publications. Therefore, it is an appropriate approach to decide which type of surgery will be used according to the experience and results of the surgeon.

Nissen fundoplication surgery, in which 360-degree wrap is performed in most centers, is considered the gold standard and is the most preferred method. In the meantime, if there is a stomach hernia, this is also repaired. If I don't have any doubts about motility disorder in my patients, I mostly use this method as floopy style.

Total fundoplication surgery was first performed by Rudolp Nissen in 1956. Today, it is widely performed both laparoscopically and floopy style. In the published guidelines, it is especially emphasized that standard procedure steps are necessary for a successful surgery (3).

It is possible to summarize the basic surgical procedures for laparoscopic Nissen fundoplication in line with the consensus of experienced surgeons: $(1,7)$

1) Opening of the phrenoesophageal ligament from left to right

2) Preservation of the hepatic branch of the anterior vagus,

3) Dissection of both crura

4) Intraabdominal mobilization of the esophagus at least $3 \mathrm{~cm}$

5) Ligation of short gastric vessels for a tension-free wrapping

6) Closing the opening between the crura with non-absorbable sutures from the posterior

7) Forming a $1.5-2 \mathrm{~cm}$ wrap, passing the most distal suture through the anterior muscle layer of the esophagus at this stage

8) The use of spark plugs in the wrapping phase (This is not required for every patient, there are opinions that it should not be used)

After the surgery, the patient is discharged within a few days. There may be temporary swallowing difficulties that can last 
for several months. Persistent, recurrent or newly developing symptoms after surgical treatment are defined as failure. Primary anti-reflux surgery has an average of $85-90 \%$ successful results over five years. Repeat anti-reflux surgery is required in approximately 3-6\% of patients. In case of failure, heartburn and regurgitation are the most common symptoms. Dysphagia is the second most common symptom.

As a result; surgery has an important place in the treatment of GERD. Surgical treatment provides sufficient improvement in the majority of patients in the early period. The minimally invasive approach has led to the widespread use of laparoscopic fundoplication surgery. Despite the recent experience, it is still necessary to be meticulous in patient selection, deciding surgery and, making decision of which method to apply. This will directly affect the success of the treatment. It should not be forgotten that it is necessary to communicate with experienced centers and specialist physicians.

\section{References}

1. Hasbahcecı M, Akçakaya A, " Gastroözofageal Reflü, Hiatal Herni ve Barrett Özofagusda Cerrahi Rehberlerin Değerlendirilmesi” Türkiye Klinikleri Genel Cerrahi Özel Dergisi 2017;10:169-80.
2. Fuchs KH, Babic B, Breithaupt W, Dallemagne B, Fingerhut A, Furnee E, et al. EAES recom mendations for the management of gastroe sophageal reflux disease. Surg Endosc 2014;28:1753-73.

3. Akçakaya A, Hasbahcecı M, "Gastroözofageal Reflüde Cerrahi Tedavi” Türkiye Klinikleri Genel Cerrahi Özel Dergisi 2017;10:1849.

4. Worrell SG, Greene CL, DeMeester TR. The state of surgical treatment of gastroe sophageal reflux disease after five decades. J Am Coll Surg 2014;219:819-30.

5. Tatarian T, Pucci MJ, Palazzo F. A Modern approach to the surgical treatment of gastroe sophageal reflux disease. J Laparoendosc Adv Surg Tech A 2016;26:174-9.

6. Moraes-Filho JP, Navarro-Rodriguez T, Bar buti R, Eisig J, Chinzon D, Bernardo W; Brazil ian Gerd Consensus Group. Guidelines for the diagnosis and management of gastroe sophageal reflux disease: an evidence-based consensus. Arq Gastroenterol 2010;47:99-115.

7. Iwakiri K, Kinoshita Y, Habu Y, Oshima T, Manabe N, Fujiwara Y, et al. Evidence-based clinical practice guidelines for gastroesopha geal reflux disease 2015. J Gastroenterol 2016;51:751-67. 